\title{
TU/e emonown

\section{First demonstration of broadcasting high capacity data in large-core POF-based in-home networks}

\section{Citation for published version (APA):}

\section{Shi, Y., Yang, H., Visani, D., Okonkwo, C. M., Boom, van den, H. P. A., Kragl, H., Tartarini, G., Randel, S.,}

Tangdiongga, E., \& Koonen, A. M. J. (2010). First demonstration of broadcasting high capacity data in large-core POF-based in-home networks. In Proceedings of the 36th European Conference and Exhibition on Optical Communication, ECOC 2010, September 19-23, 2010, Torino, Italy (pp. We.6.B.2-1/3). Institute of Electrical and Electronics Engineers.

\section{Document status and date:}

Published: 01/01/2010

\section{Document Version:}

Publisher's PDF, also known as Version of Record (includes final page, issue and volume numbers)

\section{Please check the document version of this publication:}

- A submitted manuscript is the version of the article upon submission and before peer-review. There can be important differences between the submitted version and the official published version of record. People interested in the research are advised to contact the author for the final version of the publication, or visit the $\mathrm{DOI}$ to the publisher's website.

- The final author version and the galley proof are versions of the publication after peer review.

- The final published version features the final layout of the paper including the volume, issue and page numbers.

Link to publication

\section{General rights}

Copyright and moral rights for the publications made accessible in the public portal are retained by the authors and/or other copyright owners and it is a condition of accessing publications that users recognise and abide by the legal requirements associated with these rights.

- Users may download and print one copy of any publication from the public portal for the purpose of private study or research.

- You may not further distribute the material or use it for any profit-making activity or commercial gain

- You may freely distribute the URL identifying the publication in the public portal.

If the publication is distributed under the terms of Article 25fa of the Dutch Copyright Act, indicated by the "Taverne" license above, please follow below link for the End User Agreement:

www.tue.nl/taverne

Take down policy

If you believe that this document breaches copyright please contact us at:

openaccess@tue.nl

providing details and we will investigate your claim. 


\title{
First Demonstration of Broadcasting High Capacity Data in Large-Core POF-based In-Home Networks
}

\author{
Y. Shi ${ }^{(1)}$, H. Yang ${ }^{(1)}$, D. Visani ${ }^{(1,2)}$, C.M. Okonkwo ${ }^{(1)}$, H.P.A. van den Boom ${ }^{(1)}$, H. Kragl ${ }^{(3)}$, \\ G. Tartarini ${ }^{(2)}$, S. Randel ${ }^{(4)}$, E. Tangdiongga ${ }^{(1)}$ and A.M.J. Koonen ${ }^{(1)}$
}

(1) COBRA Research Institute, Eindhoven University of Technology, P.O. Box 513, 5600 MB, Eindhoven, The Netherlands.

(2) DEIS, University of Bologna, Italy.

(3) DieMount GmbH, Wernigerode, Germany.

(4) Siemens AG, Corporate Technology, Information \& Communications, Munich, Germany.

E-mail:y.shi@tue.nl

\begin{abstract}
We report a novel low-cost in-home broadcasting system using a 1-mm core graded-index plastic optical fibre split network reaching up to 35 meters. We demonstrated broadcasting 2.5Gbit/s data to four end-users employing discrete multi-tone modulation.
\end{abstract}

\section{Introduction}

Plastic optical fibre (POF) systems recently have been shown as a cost-effective and competing broadband communication solution for shortrange communications over copper line, especially for in-home broadband access infrastructures providing Gigabit Ethernet [1]. Beyond $10 \mathrm{Gbit} / \mathrm{s}$ and $40 \mathrm{Gbit} / \mathrm{s}$ transmission over graded-index POF has been demonstrated for point-to-point links typically used for shortrange inter-connection in data centers [2, 3]. Large core POF, i.e. $1 \mathrm{~mm}$ polymethylmetacrylate (PMMA) POF, is very promising due to the potential for 'do-it-yourself' installation, easy maintenance and smaller bending radius, compared with silica singlemode or multi-mode fibres, or perfluorinated small-core POF. Low cost, robust and high capacity communication can be offered where twisted pair or coaxial cable have insufficient bandwidth and reach, therefore overcoming the last-mile broadband access bottleneck [4].

So far, most POF in-home transmission networks have been configured as point-to-point links, or point-to-multipoint ones using optoelectronic routing devices. With the emergence of POF splitters, a bi-directional POF system has been demonstrated [5]. To explore networking functions in the all-optical domain, in order to provide full signal transparency, we propose a broadcast infrastructure by cascading 1x2 POF splitters. This provides simultaneously Gigabit connectivity to several end users over lengths up to $35 \mathrm{~m}$, as shown in Fig. 1. The residential gateway $(R G)$ connects the access network to the in-home network, and the POF is used in the home to provide optical connectivity. Then the POF link is split into four floors/rooms, forming a tree topology for the transport of high capacity data. The study of in-home architectures including tree topology for point to multipoint connectivity has been presented in [6]. Here, we employ discrete multitone (DMT) modulation to maximise transmission capacity. In this paper a record 2.5Gbit/s transmission over 1x4 tree topology with a total length of $20 \mathrm{~m}$ $1 \mathrm{~mm}$ Graded Index PMMA POF is reported. Longer lengths have been also demonstrated culminating in the rates required for $1 \mathrm{Gbit}$ Ethernet for $35 \mathrm{~m}$. We believe that this paper presents the first demonstration of all-optical inhome connectivity employing large core POFs.

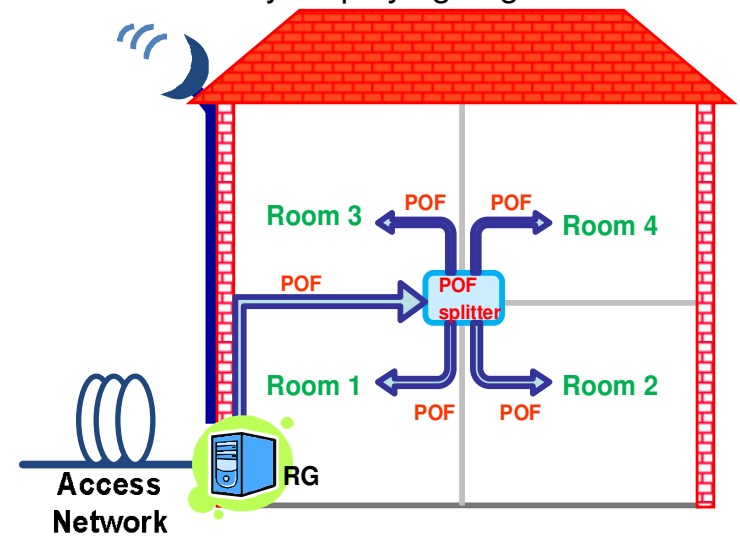

Fig. 1: All-Optical in-home broadcasting using tree topology.

\section{Experimental Setup and Discussion}

In Fig. 2, we show the experimental setup. The DMT signal is generated off-line using an arbitrary waveform generator (AWG) at a sampling rate of $3 \mathrm{GHz}$ and modulates a verticalcavity surface-emitting laser (VCSEL) with a wavelength of $667 \mathrm{~nm}$ and with a launching power of $0 \mathrm{dBm}$. This optical power meets current standards for consumer eye safety regulation. After transmission over the feeder POF (POF1), the DMT signal is coupled to a cascade of $1 \times 2$ POF splitters, which splits the signal into four ports and finally transmits over 
the distribution POFs (POF2). The launching condition of the laser into the feeder POF is such that modes are excited providing an even and stable power distribution at the output of the ports of the POF splitter. Therefore, 1x2 POF splitters used here can be similarly considered as a 50/50 splitter with $5 \mathrm{~dB}$ insertion loss. Due to the large total splitting loss of the complete 1x4 POF splitter, we demonstrate a total transmission length of $35 \mathrm{~m}$. The received signal is detected by an avalanche photodetector (APD) receiver with an active diameter of 230 $\mu \mathrm{m}$. A lens is used to match the numerical aperture of the fibre to the photoreceiver. The received signal is sampled by a digital processing oscilloscope (DPO) at $50 \mathrm{GHz}$, and then demodulated off-line in Matlab.

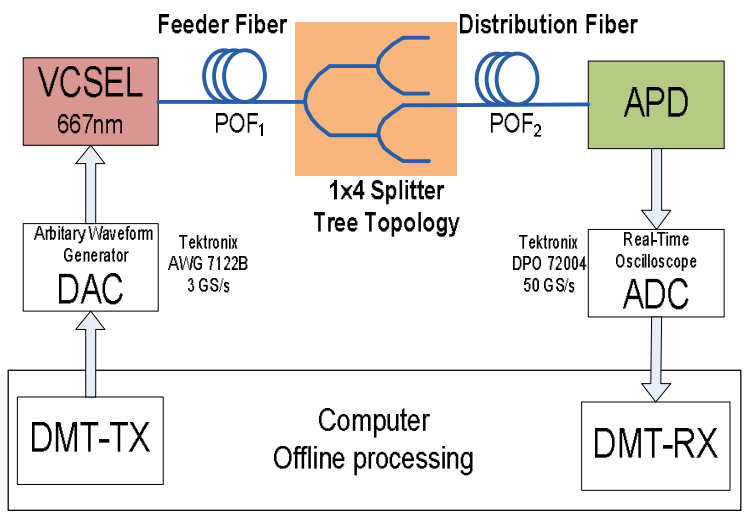

Fig. 2: Experimental Setup.

We show the bit allocation determined by the bit and power-loading algorithms and the resulting power allocation in Fig. 3 (upper) and (lower) respectively for the link including the feeder POF $\left(\mathrm{POF}_{1}=10 \mathrm{~m}\right)$ followed by the splitter and the distribution POF $\left(\mathrm{POF}_{2}=10 \mathrm{~m}\right)$. In this case, we use 256 sub-carriers for the DMT signal. The maximum bit allocation value is 2 bits per carrier. The small number of bit allocation in the low frequency is attributed to the AC-coupled receiver employed. For the higher frequency region, notice that in Fig. 3 (upper) the bit allocation is low either 0 or 1 due to the system bandwidth. The bit allocations results in a discrete mapping of the signal-to-noise ratio (SNR) to the sub-carriers index and frequency, as shown in Fig. 4 (lower). Fig. 4 (upper) illustrates the received bit error rates (BER) as a function of sub-carrier index, for the system with a total length of $20 \mathrm{~m}$. The averaged BER value in this measurement is $2 \times 10^{-4}$. In the DMT transmission, the signal is not demodulated per subcarrier but as an entire frame. This provides the benefit that even if some subcarriers have BER values larger than $10^{-3}$, the signal quality is still good enough to achieve a total average BER of below $10^{-3}$, which sets the forward-error correction (FEC) limit for error-free operation. The demodulated signal constellation diagrams are shown for two sub-carrier index groups in Fig. 5. As shown in Fig. 3 (upper), 2 bits are mainly allocated for the $30^{\text {th }}$ to $239^{\text {th }}$ sub-carrier, corresponding to the 4-QAM constellation. While only 1 bit, i.e. BPSK, is used below the $30^{\text {th }}$ and above the $240^{\text {th }}$ sub-carrier.
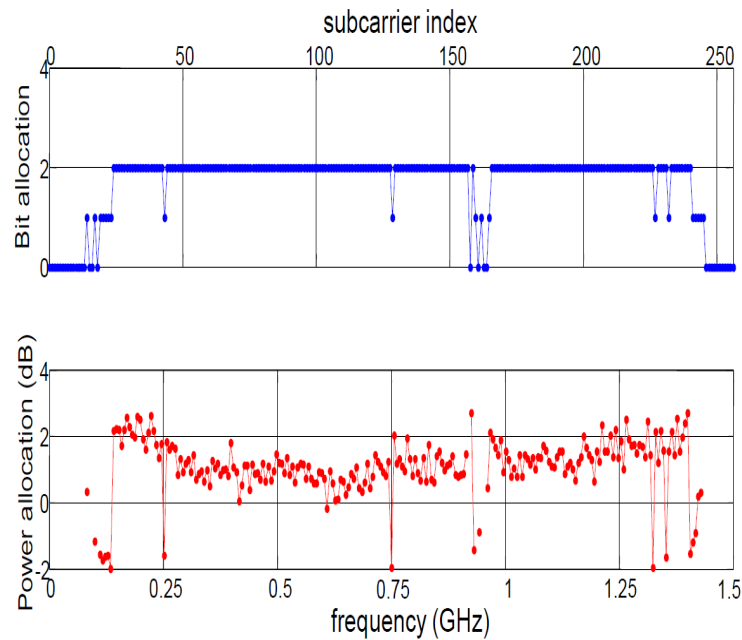

Fig. 3: Performance over 20m POF transmission (upper) Bit allocation map; (lower) Power allocation
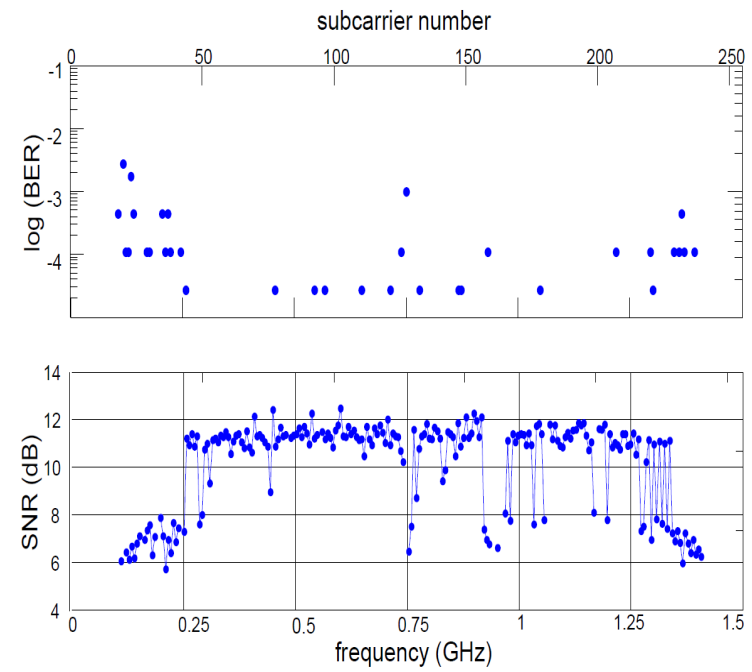

Fig. 4: BER (upper) and received SNR (lower) as a function of sub-carrier index and frequency, for the total length (POF1+Splitter + POF2 of $20 \mathrm{~m}$ ) 


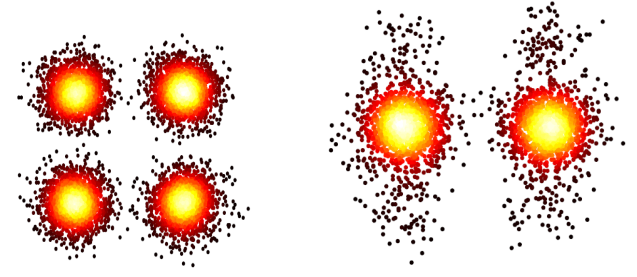

Fig. 5: Constellation diagrams of the demodulated signals; (a) 4-QAM for $51^{\text {th }}$ to $60^{\text {th }}$ and (b) BPSK for $231^{\text {th }}$ to $240^{\text {th }}$ subcarriers

Finally, we present the measured maximum bit rate for different system designs, with the total length varying from $20,25,30$ to 35 meters, and with different $\mathrm{POF}_{1}$ and $\mathrm{POF}_{2}$ length combinations, as shown in Fig. 6 and Table. 1. The maximum achieved bit rate remains larger than $1 \mathrm{Gbit} / \mathrm{s}$ for up to $30 \mathrm{~m}$ total POF length. For the total lengths below $20 \mathrm{~m}$, the bit rate is at 2.5 Gbit/s, while for lengths longer than $35 \mathrm{~m}, 1$ Giga-bit capacity cannot be exceeded mainly due to the large loss of the system (mainly attributed to the $10 \mathrm{~dB}$ loss across the $1 \times 4$ splitter) and the losses of the POF of $0.3 \mathrm{~dB} / \mathrm{m}$ at $667 \mathrm{~nm}$ wavelength.

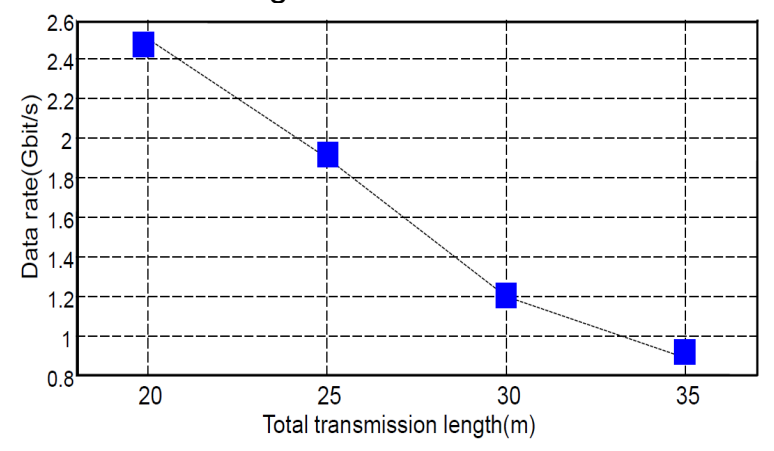

Fig. 6: The maximum bit rate for different system designs with the total length varying from $20,25,30$ and 35 meters

Table. 1 summarises the combination of lengths for the feeder and distribution POF distances before and after the splitter. The system is designed in a symmetric way so that it conforms to the requirements for in-home networks. In Table. 1, the resulting BER for each length is also measured and shown to be below the FEC limit, so that sufficient BER margin is achieved.
Table. 1: Data rate with different POF1 and POF2 length combinations

\begin{tabular}{|c|c|c|c|c|}
\hline POF 1 & POF 2 & Total & Data rate & BER \\
\hline $10 \mathrm{~m}$ & $10 \mathrm{~m}$ & $20 \mathrm{~m}$ & $2.5 \mathrm{Gbit} / \mathrm{s}$ & $2 \mathrm{e}-4$ \\
\hline $15 \mathrm{~m}$ & $10 \mathrm{~m}$ & $25 \mathrm{~m}$ & $1.9 \mathrm{Gbit} / \mathrm{s}$ & $1.7 \mathrm{e}-4$ \\
\hline $15 \mathrm{~m}$ & $15 \mathrm{~m}$ & $30 \mathrm{~m}$ & $1.2 \mathrm{Gbit} / \mathrm{s}$ & $6.9 \mathrm{e}-4$ \\
\hline $20 \mathrm{~m}$ & $15 \mathrm{~m}$ & $35 \mathrm{~m}$ & $0.89 \mathrm{Gbit} / \mathrm{s}$ & $4 \mathrm{e}-4$ \\
\hline
\end{tabular}

\section{Conclusions}

We report for the first time multi-gigabit transmission in a 1:4 all-optically split network using large-core graded-index POF We demonstrated a tree topology for the in-home network connectivity. Using the same components, we can also build other topologies such as passive bus and star architectures. Here we employed 1x2 POF splitters to construct a $1 \times 4$ tree topology interconnecting the residential gateway with the rooms by feeder and distribution POF links. Using realistic fibre lengths $(10,25,30$ and $35 \mathrm{~m})$ applicable to the in-home network environment, we demonstrated multi-gigabit transmission with bit-error rate performance around $10^{-4}$. We believe that with the solution proposed here consisting of eyesafe low-power transmitters and low-cost receivers, an easy-to-install POF all-optically split network can provide a promising solution for high-speed in-home broadband communication.

\section{Acknowledgement}

The work in this paper is supported by EU program FP7 ICT-224521 POF-PLUS and Dutch Program IOP-GenCom IGC0507 on Future Home Networks.

\section{References}

1 S. Randel et al, ECOC'06, PDP4 (2006).

$2 \mathrm{H}$.Yang et. al, Optics Letters ,35,5,730(2010)

$3 \mathrm{H}$.Yang et al. J. Lightwave.Tech. 28, 4,352, (2010)

4 A.M.J. Koonen et al, ECOC'07,(2007)

5 A. Antonino et al., OFC (2010), Paper OWA7

6 A.M.J. Koonen et al, ECOC'09 (2009) 